\title{
LOCALISATION OF CHIASMATA IN CEPAEA NEMORALIS L.
}

\author{
C. R. BANTOCK \\ Department of Biology and Geology, Polytechnic of North London, London, N.7
}

Received 6.xii.71

\section{INTRODUCTION}

IT is well known that most populations of Cepaea nemoralis $\mathrm{L}$. exhibit the following three features:

1. A high degree of genetic polymorphism affecting the colour and banding patterns of the shell.

2. Strong linkage between many of the relevant loci.

3. Linkage disequilibrium, so that a population may show, for example, an excess of the pink unbanded phenotype relative to the proportions of pink banded, yellow unbanded and yellow banded (e.g. GuerrucciHenrion, 1966).

The colour and banding polymorphism entails at least five and possibly six linked loci (Cook, 1967; Cain, Sheppard and King, 1968), and the data from the breeding programmes (Lamotte, 1954; Cain and Sheppard, 1957; Cain, King and Sheppard, 1960; Cain, Sheppard and King loc cit.; Cook loc. cit.) show that the linkage is very tight with usually little or no apparent recombination. Cepaea is thus frequently stated to possess a supergene (e.g. Ford, 1964).

Very little is known of the cytology of Cepaea beyond the fact that the haploid chromosome number is 22 (Perrot, 1938) and that one metacentric chromosome is much larger than any of the others.

The work described in this paper was undertaken in an attempt to elucidate some of the properties of the nuclear phenotype during meiosis with a view to throwing light on a possible visible cytological basis to the strong linkage.

\section{Materials and methods}

Adult individuals of $C$. nemoralis were collected between January and March 1971 from various colonies known to the author. These snails were used for establishing a satisfactory technique for chromosomal analysis. In addition, detailed observations were made on spermatocytes from individuals taken from a colony near the top of Haddon Hill in Exmoor, Somerset. The colony is interesting in that not only is it polymorphic for colour (dark pink and dark yellow) and banding (unbanded or banded), but also for lip colour (dark or white). The colony shows strong linkage disequilibrium. The result of a sample of adults taken without conscious

\section{TABLE 1}

Grid Ref.

DP0nl. DP0al. DP3nl.

$73 \quad 17 \quad 16$

DP3al. DP5nl.

DY0nl. Total 
bias from this colony in July 1970 is given in table 1, scored using the nomenclature agreed at the 2 nd International Conference on Snail Genetics at York 1967. The snails were kept at $16 \pm 1^{\circ} \mathrm{C}$., in plastic boxes containing damp filter paper and were fed on carrot. Natural chalk was always available.

Ordinary squash methods do not give satisfactory preparations of meiotic chromosomes. Accordingly the method originally developed for the study of human mitotic metaphases and subsequently extended to that of mammalian meiosis (e.g. Evans, Breckon and Ford, 1964) was modified for spermatocyte divisions. The method employed involves the use of pretreatments (colchicine followed by hypotonic citrate), and since the procedure mayprove to be of general application to the chromosomal analysis of Cepaea the technique is described in full.

1. The shell of the live adult was removed by cutting round the top of the whorls in a continuous cut starting at the aperture.

2. The whole animal was pinned in a small waxed dish and covered with Helix saline (Lockwood, 1963).

3. The entire ovotestis was removed by cutting along the mantle edge close to the columellar surface of the visceral hump and dissecting away the digestive gland.

4. The ovotestis was placed in a solid watch glass containing $1 \mathrm{ml}$. 0.04 per cent. colchicine in Helix saline.

5. The ovotestis consists of numerous blind ending diverticula (follicles) opening proximally into tubules. These fuse and lead into the upper end of the hermaphrodite duct. The follicles were broken with dissecting needles and teased so that the contents was released. Sections of the ovotestis have shown that dividing spermatocytes tend to be found near the distal ends of the follicles; a greater yield of dividing cells is obtained if each of a small number of follicles is teased individually than if the whole gland is only roughly teased.

The total exposure time to colchicine was $30 \mathrm{~min}$.

6. Tubule fragments and unteased gonad were removed. The cells liberated from the ovotestis were transferred to two $1 \mathrm{~cm} \cdot{ }^{3}$ centrifuge tubes. Oocytes, which can usually be recognised even with the naked eye, were not so transferred. The tubes were spun for $30 \mathrm{sec}$. at 1000 r.p.m. and the supernatant was removed without disturbing the pellet. Each tube was then allowed to drain for about $45 \mathrm{sec}$. and the remainder of the supernatant was then removed. (Examination of the supernatant showed that it contained only sperm.) Each tube was then two-thirds filled with 2.0 per cent. tris sodium citrate. As this was added the pellet was resuspended by flushing with the pipette. The tubes were then allowed to stand for $10 \mathrm{~min}$.

7. The centrifugation treatment described in 6 above was repeated and the citrate removed, again allowing the tubes to drain. $1 \cdot 0$ per cent. citrate was added and the pellet resuspended. The tubes were stood for a further $10 \mathrm{~min}$.

8. Fixation was carried out with the cells in suspension. It was found that this resulted in fewer of the cells clumping than if the pellet as such was fixed. The tubes were centrifuged as before and two-thirds of the citrate removed. Each pellet was then disrupted by careful flushing until the cells were evenly dispersed through the fluid. Fixative (absolute ethanol/glacial acetic acid $3: 1$ ) was added a drop at a time and then more quickly until 
the tube was nearly full. The cells were then taken through two changes of fixative as quickly as possible and allowed to stand for $1 \mathrm{hr}$. in suspension.

9. Air-dried films were made by taking up a drop of the suspension and allowing 3-4 drops to fall on a glass slide from a distance of about $4 \mathrm{~cm}$. When the fixative had evaporated the process was repeated until a sufficient density of cells (as assessed by low power light microscopy) was reached.

10. The films were stained in 5 per cent. lacto-propionic orcein for $\frac{1}{2}-1 \mathrm{hr}$, , washed in 45 per cent. acetic acid, taken through three changes of cellosolve, cleared in michrome essence and mounted in michrome.

\section{Comments}

(a) The sperm of Cepaea is still motile after $1 \mathrm{hr}$. in Helix saline at room temperature. It has therefore been assumed that this saline is suitable.

(b) Stock solutions of saline and saline with colchicine were kept at $4^{\circ} \mathrm{C}$. and allowed to come to room temperature before use.

(c) The citrate and fixative solutions were freshly prepared.

(d) Other concentrations of citrate have been tried; very weak concentrations (e.g. 0.01 per cent.) are clearly toxic since they result in the loss of visible nuclear structure. Since the percentages indicated above gave adequate results they were used regularly, but it would probably be possible to obtain improved separation of the chromosomes or bivalents with different strengths or solutions.

(e) The most satisfactory fixation is achieved if the cell pellet is not larger than $2 \mathrm{~cm}^{3}$.

$(f)$ Most gonads yield enough cells to make films on four 3 in. $\times 1.5$ in. (approx. $7.5 \mathrm{~cm} . \times 4.0 \mathrm{~cm}$.) slides.

The method outlined above gives both meiotic and mitotic figures at least between January and June in this country. More than 100 diplotene and/or diakinetic cells can sometimes by obtained from one individual.

\section{RESULTS}

It can be seen that approximately 14 per cent. of the individuals from the Haddon Hill colony have white lips and that the population shows strong linkage disequilibrium in that there are no yellow bandeds, nor yellows with white lips. Presumably therefore $\mathrm{C}^{\mathrm{DY}}, \mathrm{B}^{\mathrm{O}}$ and $\mathrm{P}^{\mathrm{B}}$ are strongly linked. No recombinants have been found on subsequent sampling of this population. The colony is ecogenetically interesting in that it appears to conform with the geographical distribution of the white-lipped phenotype. There is a positive correlation between the frequency of the $\mathrm{P}^{\mathrm{A}}$ allele of the $\mathrm{P}$ locus and rainfall (Gain, 1971). Haddon Hill is over $1000 \mathrm{ft}$. $(300 \mathrm{~m}$.) high and presumably has a rainfall characteristic of the rest of Exmoor: 50-60 in. (approx. $145 \mathrm{~cm}$.) per annum (Manley, 1952).

\section{The chromosome complement}

Perrot's 1938 finding that the haploid chromosome number is 22 is confirmed. Furthermore, it is possible to distinguish between three groups of chromosomes (plate I, 1). 
(a) The large pair already referred to. In mitotic metaphases the chromosomes of this group measure approximately $7 \mu \mathrm{m}$. and are clearly metacentric. In this paper they will be referred to as the A group.

(b) A pair of (metacentric) chromosomes approximately $3 \mu \mathrm{m}$. long at metaphase. This pair will be referred to as the $\mathrm{B}$ pair.

(c) The C group, consisting of 20 pairs of (chiefly metacentric) chromosomes, the smallest of which is probably less than $1 \mu \mathrm{m}$. long. No attempt has yet been made to categorise the chromosomes of this group further.

\section{Spermatocyte meiotic chromosomes}

During zygotene (plate $I, 2$ ) it is not possible to identify any chromosome pair individually. Where the chromosomes are at all clear it can be seen that synapsis seems to be complete; there are no obvious signs of failure or other abnormality of pairing. During late pachytene individual bivalents become recognisable but it is not until diplotene that the distribution of

\begin{tabular}{|c|c|c|c|c|c|c|c|c|}
\hline \multirow[b]{3}{*}{ Morph } & \multirow{3}{*}{$\begin{array}{l}\text { Nos. of } \\
\text { cells }\end{array}$} & \multicolumn{5}{|c|}{ A group } & \multicolumn{2}{|c|}{$\mathrm{B}+\mathrm{C}$ group } \\
\hline & & \multicolumn{2}{|c|}{$\begin{array}{l}\text { No. of } \\
\text { proximal } \\
\text { Xta }\end{array}$} & \multicolumn{2}{|c|}{$\begin{array}{c}\text { No. of } \\
\text { pro-terminal } \\
\text { Xta }\end{array}$} & \multirow{2}{*}{$\begin{array}{l}\text { Percentage } \\
\text { pro-terminal } \\
\text { Xta }\end{array}$} & \multirow[b]{2}{*}{$\begin{array}{l}\text { Total } \\
\text { Xta }\end{array}$} & \multirow[b]{2}{*}{$\begin{array}{l}\text { Xta per } \\
\text { cell }\end{array}$} \\
\hline & & 1 & 2 & 1 & 2 & & & \\
\hline 1. DP0nl. & 100 & 100 & 0 & 4 & 0 & $2 \cdot 0$ & 2100 & 21 \\
\hline 2. DP0nl. & 30 & 30 & 0 & 3 & 1 & $8 \cdot 3$ & 630 & 21 \\
\hline 3. DP0nl. & 28 & 28 & 0 & 3 & 0 & $5 \cdot 4$ & 788 & 21 \\
\hline 4. DPOnl. & 72 & 71 & 1 & 22 & 3 & $19 \cdot 4$ & 1512 & 21 \\
\hline 5. DP0nl. & 70 & 70 & 0 & 35 & 15 & $46 \cdot 4$ & 1470 & 21 \\
\hline 6. DP0al. & 65 & 65 & 0 & 8 & 0 & $6 \cdot 2$ & 1365 & 21 \\
\hline 7. DY0nl. & 56 & 56 & 0 & 7 & 3 & $11 \cdot 6$ & 1141 & 21 \\
\hline 8. DYOnl. & 58 & 58 & 0 & 5 & 0 & $4 \cdot 3$ & 1218 & 21 \\
\hline 9. DYOnl. & 136 & 134 & 2 & 10 & 0 & $3 \cdot 7$ & 2856 & 21 \\
\hline 10. DY0nl. & 32 & 32 & 0 & 11 & 3 & $26 \cdot 6$ & 672 & 21 \\
\hline 11. DY0nl. & 38 & 38 & 0 & 0 & 0 & 0 & 581 & 21 \\
\hline 12. DYOnl. & 32 & 31 & 1 & 1 & 0 & $1 \cdot 6$ & 661 & 21 \\
\hline 13. DP3nl. & 35 & 35 & 0 & 7 & 0 & $10 \cdot 0$ & 721 & 21 \\
\hline 14. DP3nI. & 30 & 30 & 0 & 2 & 1 & 6.7 & 630 & 21 \\
\hline
\end{tabular}

chiasmata can be made out. During pachytene and early diplotene the chromosomes have a lampbrush appearance and bivalent repulsion is occasionally impeded by apparent "stickiness" of the homologues so that these are sometimes held together at points other than those where chiasmata have formed. In later diplotene and diakinetic cells (plate I, 3-8) the distribution of chiasmata becomes clear and in these cells it is usually possible to distinguish between all three groups of bivalent (A, B and $\mathrm{C})$.

Detailed observations have been made on chiasmata in 800 spermatocytes in 25 individuals from the colony on Haddon Hill described earlier. In eight individuals, none of the cells were at suitable stages for examination. The results from those individuals which yielded 25 or more cells are summarised in Table 2. 


\section{(a) A Group}

Chiasmata in the bivalent of this group fall into two categories, proximal and pro-terminal.

\section{(i) Proximal}

It can be seen from table 2 that in 778 of the 782 spermatocytes the A group bivalent possesses only a single proximal chiasma (plate I, 3, 5-8). This appears to be always in the same position. Since the arms of the cross so formed are long, these occasionally overlap, but it is possible to distinguish between these overlaps and chiasmata. In the other four spermatocytes (from three different individuals) there are two proximal chiasmata (plate I, 4 ), neither of these apparently corresponding in position to the single chiasma usually found. It is not possible at present to say what relationship the positions of these chiasmata bear to the centromere.

\section{(ii) Pro-terminal}

In 144 of the spermatocytes, in addition to the single proximal chiasma, what appear to be pro-terminal chiasmata are present. The position of these varies slightly. In some diplotene cells chiasmata appear to be formed very close to the ends of the bivalent so that in these cases the chiasmata can be recognised only by the separation of the sister chromatids and by an association between the ends of the non-sister chromatids (plate I, 5). It is possible that these associations are not chiasmata at all but are caused by a persistent terminal stickiness between the homologues, but since these points of contact persist into diakinesis (plate $I, 6$ ) it is more likely that they do in fact represent chiasmata formed very close to the ends of the bivalents and they have therefore been included as such in table 2 . In other cases what is clearly a proterminal chiasma is identifiable (plate I, 7). Twenty-six of the spermatocytes have pro-terminal chiasmata at both ends of the arms of the A group bivalent (plate I, 8). Pro-terminal chiasmata did not occur in the four spermatocytes with two proximal chiasmata.

It is clear from table 2 that there are considerable differences between different individuals in the frequency of pro-terminal chiasmata in the A group bivalent. It is possible (though presumably rather unlikely) that there may be differences between different morphs in any one population. Analysis of variance gives a variance ratio of 0.410 ; with 2 and 11 degrees of freedom this is not significant at the 5 per cent. level. (Since only one of the DP0al. individuals yielded cells suitable for examination this was included with the other dark pink unbandeds.)

\section{(b) $B$ group}

Where the bivalent of this group is distinguishable from those of the $\mathrm{C}$ group it can be seen to possess a single proximal chiasma (plate I, 4,7 ).

\section{(c) $C$ group}

All the bivalents of this group regularly have one chiasma. There are clearly differences in chiasma position between the different bivalents of this group; some have single pro-terminal chiasmata, others have proximal chiasmata, but since it is not possible to identify the bivalents individually 
it is not possible at present to determine whether the chiasma in any one bivalent invariably forms in the same position.

\section{Discussion and conglusions}

The data presented suggests that in the population that has been analysed in detail spermatocyte chiasmata are both low in number and with respect to the A group bivalent localised in position. It has long been held (e.g. Darlington, 1929) that the formation of chiasmata not only ensures intra-chromosomal recombination but by preventing total bivalent repulsion at diakinesis ensures the orderly separation of the homologues at anaphase $I$. If this is the case, then the spermatocytes of $C$. nemoralis generally possess the minimum number of chiasmata to ensure this. It seems that at least in the case of the A group bivalent there is a high degree of positive interference in that in the four cases where the single proximal chiasma is missing two chiasmata are formed at points where these do not otherwise occur. Apart from these four exceptional cases, variation in chiasma position and frequency in this group depends entirely on the formation of pro-terminal chiasmata in some of the bivalents, associations which in some cases may not be chiasmata at all.

Although many cases are known (e.g. Chandley, 1968; Henderson, $1969 a$ ) where chiasma position and frequency can be altered experimentally, it is likely that chiasma formation is under genetic control (Barker, 1960; Henderson loc. cit.). Nothing is known of the heritability of chiasma formation in Cepaea. Lewis and John (1964) have suggested that differences between different cells in the same individual could be caused by small variations in the cytoplasmic environments of the cells concerned. There is no reason to suppose that this could not apply to Cepaea; if it does, then the response to such differences is more sensitive at the ends of the A group bivalent than proximally where there is very little variation. Differences in chiasma frequency due to sex are well known, but in view of the fact that Cepaea is hermaphrodite it is rather likely that differences between the male and female parts of the gonad would be small.

The cause of chiasma localisation is unknown. Henderson (1969b) found that extensive failure of zygotene pairing resulted in a localised distribution of chiasmata in the grasshopper Chrysochraon dispar, and suggested that failure of pairing could be a general cause of chiasma localisation in other cases. This would appear not to apply to Cepaea, where zygotene pairing seems to be relatively complete. On the other hand, as Henderson (1970) has suggested, it is possible that the distribution of chiasmata may be determined by the positions of formation of synaptinemal complex (electrondense material) between the homologues in early meiotic prophase; if this is limited in distribution, then localised chiasmata would result even in the presence of complete synapsis as assessed by light microscopy. Nothing is known of the electron-microscopic structure of the chromosomes of Cepaea; this would be worth investigation.

A second cause of localisation of chiasmata could be structural rearrangements. Cain and Sheppard (1954) suggested that the strong linkage in Cepaea could be due to the presence of an appropriate chromosomal inversion. The present work gives no information on the occurrence of structural rearrangements, and owing to the difficulty of analysing zygotene nuclei in Cepaea it is doubtful whether conventional staining of air-dried films will 
yield information on this point. On the other hand several authors (e.g. Seabright, 1971; Sumner, Evans and Buckland, 1971) have recently described techniques whereby it is possible to identify individual pairs of (human lymphocyte) chromosomes by the distribution of specific banding patterns obtained by partial enzyme or alkali digestion of air-dried chromosomes. This technique may well throw light on the possible occurrence and distribution of major structural rearrangements in Cepaea.

It is useful to speculate on the significance of chiasma localisation. Much attention has been given to the evolutionary aspects of linkage and recombination (e.g. Bodmer and Parsons, 1962; White, 1965); it is one of the central beliefs of much modern evolutionary thought that selection acts not only on the properties of single genes but also on the properties of interacting (epistatic) genes. Whilst recombination frequency must presumably govern the release of intra-chromosomal variability by a population, Turner (1967) has argued that under conditions of random mating and constant selective pressures, polymorphic populations with linkage disequilibrium (gametic excess) are always subject to epistatic selection in favour of reduced recombination between the relevant loci. Under such conditions coadapted gene complexes will evolve characterised by the possession of large linkage groups (supergenes) within which there is little recombination. Cook (1967) has calculated that the probability of six of the nine loci involved in the colour and banding polymorphism of Cepaea lying on the large chromosome (A group) is $4 \times 10^{-7}$. Although there is at present no indication that this is indeed the case, it is clear that the chromosomes of $C$. nemoralis, and that either arm (but not both arms together) of the A chromosome in particular, present an admirable vehicle for the evolution of large permanent linkage groups in that the conditions required for the possession of a supergene are satisfied. The low frequency of cytological cross-overs in certain parts of the A group bivalent is not inconsistent with the low frequency of recombinants in the breeding programmes. Obviously the colour and banding supergene occupies only a very small part of the total available chromosomal space; if it is on either arm of the A chromosome then it presumably contains or is linked to numerous other loci not yet identified. A preliminary investigation of several other polymorphic populations of this species, and of the closely related $C$. hortensis (Müller), suggests that the restriction to a single proximal chiasma in the A group bivalent is widespread in both species. On the other hand, $C$. nemoralis is monomorphic for colour (dark pink) over a large part (at least $60 \mathrm{sq} . \mathrm{km}$.) of its British range in that part of Somerset lying between the Brendon Hills and the Quantocks (Bantock, unpublished data; and see Bantock, 1971). Whilst the cytological data has not yet been fully analysed, a preliminary investigation of meiosis in one population from this area suggests that there is greater variation in the number and position of chiasmata in the A group bivalent than in the highly polymorphic population described in this paper. The significance of this cannot be assessed until more is known about the range of variation in chiasma position and frequency in a larger number of populations. If indeed monomorphism at the loci so far identified is regularly associated with increased variation in cross-over position and frequency in the A group bivalent, then it might follow that the visually much less polymorphic continental species of Cepaea, C. sylvatica (Drap.) and C. vindobonensis (Pfeif.) would also show less restricted chiasma formation. 


\section{Summary}

1. A technique for the examination of the chromosomes of $C$. nemoralis is described.

2. The haploid chromosome number is 22. Three types of chromosome can be recognised; a large pair (A group), an intermediate sized pair ( $B$ group), and 20 pairs of small chromosomes (G group).

3. The frequency and distribution of chiasmata have been examined in 782 spermatocytes from individuals in a highly polymorphic population showing strong linkage disequilibrium.

4. Chiasmata are limited in number and apparently localised in position. All the bivalents possess only a single chiasma except that in some cases the A group bivalent may possess one or two pro-terminal chiasmata as well as a single proximal one. Exceptionally, two proximal chiasmata are formed in this bivalent.

5. The evolutionary implications of chiasma localisation are discussed.

Acknowledgments.-I am grateful to the Governing Body of the Polytechnic of North London for financial assistance.

I am also grateful to Mr J. A. Bayley of the Leonard Wills Field Centre and to the late Miss L. Narayanan for help with the collection of snails. I should like to thank the following Technical Staff of the Polytechnic of North London for their assistance: Miss L. Hartwell, Mr R. Haveley and Mrs O. Owen.

\section{REFERENGES}

BANTOCK, G. R. 1971. Natural selection in experimental populations of Cepaea hortensis. 7. biol. Educ., 5, 25-34.

BARKER, J. F. 1960. Variation of chiasma frequency in and between natural populations of Acrididae. Heredity, 14, 211-214.

BODMER, W. F., AND PARSONs, P. A. 1962. Linkage and recombination in evolution. Advances in Genetics, 11, 1-100.

GAIN, A. J. 1971. Colour and banding morphs in subfossil samples of the snail Cepaea. In Ecological Genetics and Evolution (ed. R. Creed), 65-92. Blackwell Scientific Publications, Oxford and Edinburgh.

CAIN, A. J., AND SHePpard, P. M. 1954. Natural selection in Cepaea. Genetics, 39, 89-116.

CAIN, A. J., AND SHEPPARD, P. M. 1957. Some breeding experiments with Cepaea nemoralis. 7. Genetics, 55, 195-199.

CAIN, A. J., KING, J. M. B., AND SHEPpARD, P. M. 1960. New data on the genetics of polymorphism in the snail Cepaea nemoralis. Genetics, 45, 393-411.

CAIN, A. J., SHePPARD, P. M., AND KING, J. M. B. 1968. Studies on Cepaea. I. The genetics of some morphs and varieties of Cepaea nemoralis (L.). Phil. Trans. Roy. Soc. (Ser. B), $253,383-396$.

GHANDlEy, A. c. 1968. The effect of X-rays on female germ cells of $D$. melanogaster. III. A comparison with heat treatment on crossing-over in the $\mathrm{X}$-chromosome. Mutation Res., 5 (1), 93-107.

cooK, L. м. 1967. The genetics of Cepaea nemoralis. Heredity, 22, 397-410.

DARlington, c. D. 1929. Meiosis in polyploids. II. Aneuploid hyacinths. 7. Genet., 21, 17-56.

EVANS, E. P., BREGKON, G., AND FORD, C. E. 1964. An air-drying method for meiotic preparations from mammalian testes. Cytogenetics, 3, 289-294.

FORD, E. B. 1964. Ecological Genetics. Methuen, London; Wiley, New York.

GUERRUGCI-HENRION, M.-A. 1966. Recherches sur les populations naturelles de Cepaea nemoralis en Bretagne. Archs. Zool. exp. gen., 107, 369-417.

HENDERSON, s. A. 1969a. Chromosome pairing, chiasmata and crossing over. In Handbook of Molecular Cytology (ed. A. Lima-de-Faria), 15, 326-357. North-Holland Publ. Co., Amsterdam.

HeNderson, s. A. 1969b. Chiasma localisation and crossing over. In Chromosomes Today (ed. Darlington, C. D., and Lewis, K. R.), 2, 56-60. Oliver and Boyd, Edinburgh. 


\section{Plate 1}

Spermatocytes of C. nemoralis. $\times 1250$.

1. Mitotic prophase. The A and B chromosomes are clearly distinguishable from the others (C chromosomes).

2. Late zygotene. None of the bivalents can be individually identified. Synapsis seems to be complete.

3. Early diakinesis. All the bivalents have one chiasma.

4. Late diplotene. In this cell the $\mathrm{A}$ group bivalent has two proximal chiasmata.

5. Late diplotene. 6. Late diakinesis. In these cells the A group bivalents have one proximal chiasma and a terminal association which is probably a pro-terminal chiasma.

7. Diplotene. In this cell the $\mathrm{A}$ group bivalent has a proximal chiasma and one proterminal chiasma.

8. Late diplotene. In this cell the A group bivalent has one proximal chiasma and two pro-terminal chiasmata. 


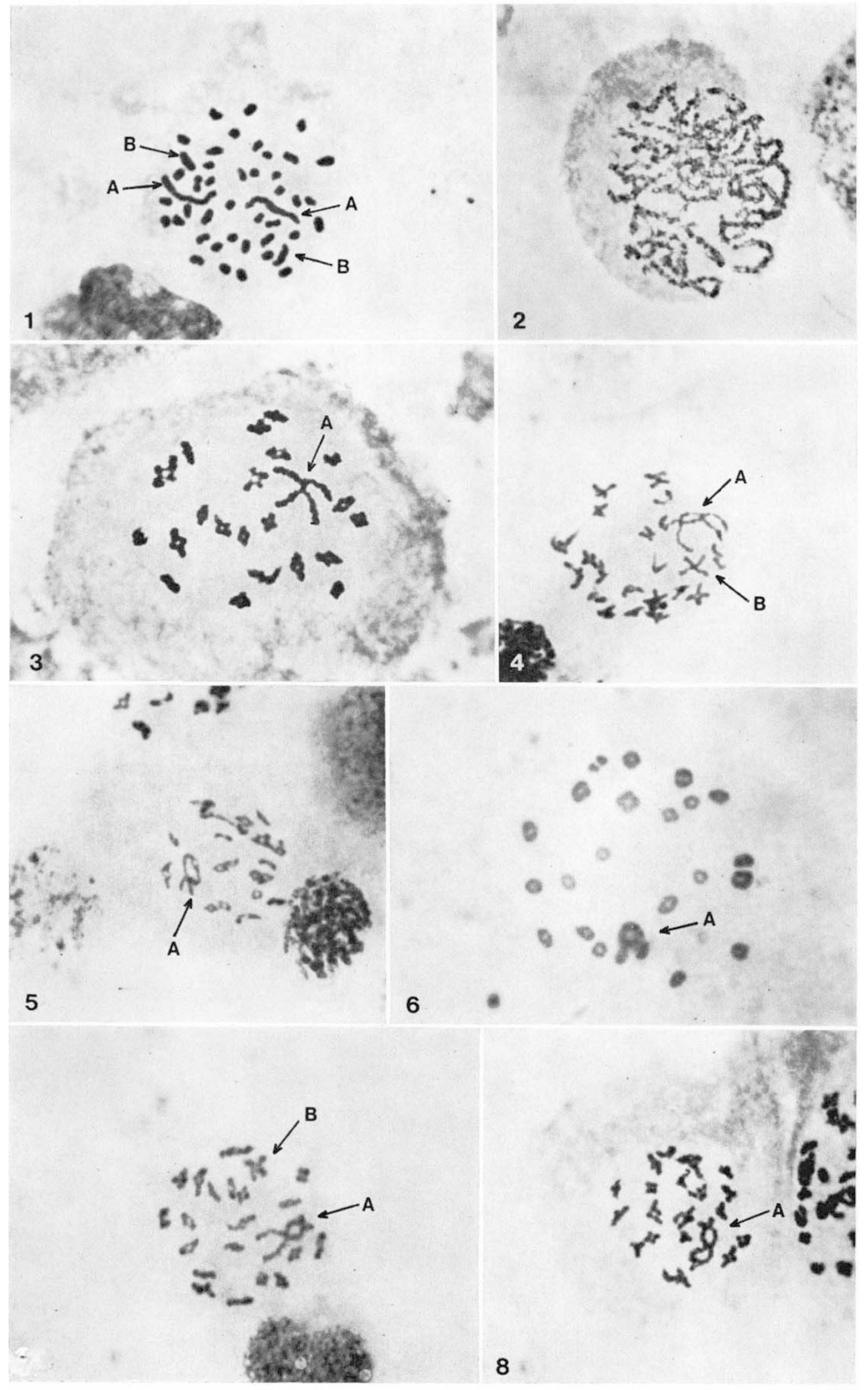


henderson, s. A. 1970. The time and place of meiotic crossing-over. Ann. Rev. Gen., 4, 295-324.

LAMOTTE, M. 1954. Sur le déterminisme génétique du polymorphisme chez Cepaea nemoralis L. Compt. Rend. Acad. Sci. Paris, 239, 365-367.

Lockwoon, A. P. м. 1963. Animal Body Fluids and their Regulation. Heineman, London. LEWIS, K. R., AND JOHN, B. 1964. The Matter of Mendelian Heredity. Churchill, London. MANLEY, G. 1952. Climate and the British Scene. Collins, London.

PERROT, M. 1938. Etude de cytologie comparée chez les gasteropodes pulmonés. Rev. Suisse de Zool., 45, 487-566.

SEABRIGHT, M. 1971. A rapid banding technique for human chromosomes. The Lancet, 2 (No. 7731), 971-972.

SUMNER, A. T., EVANS, H. J., AND BUGKLAND, R. A. 1971. New techniques for distinguishing between human chromosomes. Nature New Biology, 232, 31-32.

TURNER, J. R. G. 1967. On supergenes. I. The evolution of supergenes. The Amer. Natur. $101,195-221$.

White, M. J. D. 1965. Principles of karyotypic evolution in animals. Proc. XI Int. Congr. Genetics, in Genetics Today, 2. 